
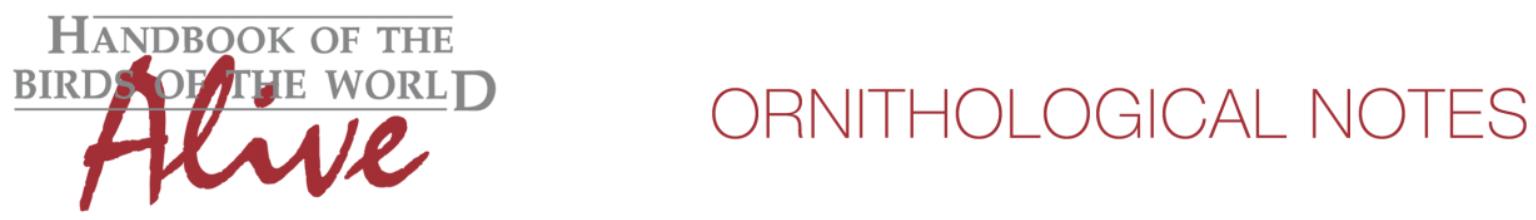

\title{
Notes on the vocalizations of Barred Antshrike (Thamnophilus doliatus)
}

Peter Boesman

In the following we briefly analyze and compare voice of the different races of Barred Antshrike (Thamnophilus doliatus). We also try to quantify the extent of any vocal differences using the criteria proposed by Tobias et al. (2010), as a support for taxonomic review. We have made use of sound recordings available on-line from Xeno Canto (XC).

When listening to the loudsong of the many subspecies of Barred Antshrike, it becomes quickly apparent that there are some vocal differences between races north and south of the Amazon river.

Furthermore, the caatinga race capistratus was proposed as a separate species (Assis et al. 2007), for which we will consider this as a third group in our comparison (Fig. 1).

We have taken a random sample of 10 songs for each of the following 3 groups: capistratus, races north of the Amazon and races $\mathrm{S}$ of the Amazon (excl. capistratus). We measured several basic sound parameters, and given that differences may be rather small, we have calculated for all average, standard deviation and effect size in order to reach calculated scores.

\section{capistratus}

total length

\# notes

max pace*

length last note

max. freq. start

max. freq. middle

max. freq end

max. freq last note

delta end vs last note

\section{$\mathbf{N}$ of Amazon}

total length

\# notes

max pace

length last note

max. freq. start

max. freq. middle

max. freq end

max. freq last note

delta end vs last note

$\begin{array}{lll}\text { data range } & \mathrm{Av} & \mathrm{SD} \\ 2.09-3.0 & 2.56 & 0.32 \\ 14-20 & 17.9 & 2.13 \\ 0.094-0.115 & 0.101 & 0.008 \\ 0.11-0.21 & 0.158 & 0.034 \\ 750-1120 & 937 & 171 \\ 720-930 & 852 & 56 \\ 640-780 & 730 & 40 \\ 620-790 & 745 & 51 \\ -20 \text { to } 55 & 15 & 26\end{array}$

$\begin{array}{lll}\text { data range } & \text { Av } & \text { SD } \\ 2.48-3.6 & 2.94 & 0.39 \\ 20-30 & 25.9 & 4.4 \\ 0.07-0.1 & 0.088 & 0.011 \\ 0.11-0.165 & 0.135 & 0.017 \\ 700-940 & 836 & 75 \\ 870-1000 & 945 & 46 \\ 750-920 & 860 & 56 \\ 800-1040 & 940 & 85 \\ 30-180 & 80 & 48\end{array}$




\section{S of Amazon}

$\begin{array}{llll} & \text { data range } & \text { Av } & \text { SD } \\ \text { total length } & 1.9-2.76 & & \\ \text { \# notes } & 12-20 & 2.24 & 0.29 \\ \text { max pace } & 0.08-0.16 & 14.9 & 2.4 \\ \text { length last note } & 0.105-0.20 & 0.12 & 0.021 \\ \text { max. freq. start } & 1000-1340 & 0.137 & 0.027 \\ \text { max. freq. middle } & 960-1200 & 1102 & 103 \\ \text { max. freq end } & 718-900 & 1112 & 132 \\ \text { max. freq last note } & 730-990 & 786 & 69 \\ \text { delta end vs last note } & 25-210 & 877 & 90 \\ & & 89 & 57 \\ \text { * pace is here measured by the period, duration between } 2 & & \\ \end{array}$

\section{Effect size}

$\begin{array}{llll} & \begin{array}{l}\text { capistratus } \\ \text { vs North }\end{array} & \begin{array}{l}\text { capistratus } \\ \text { vs South }\end{array} & \text { North vs South } \\ \text { total length } & 1.065 & 1.048 & 2.037 \\ \text { \# notes } & 2.31 & 1.32 & 3.1 \\ \text { max pace } & 1.35 & 1.20 & 1.91 \\ \text { length last note } & 0.86 & 0.68 & 0.089 \\ \text { max. freq. start } & 0.76 & 1.17 & 2.95 \\ \text { max. freq. middle } & 1.81 & 2.56 & 1.69 \\ \text { max. freq end } & 2.67 & 0.99 & 1.18 \\ \text { max. freq last note } & 2.78 & 1.8 & 0.72 \\ \text { delta end vs last note } & 1.68 & 1.67 & 0.17\end{array}$

Assis et al. (2009) state that capistratus has 'more elements' and 'longer final element' . The former could be confirmed, although with considerable overlap. Length of final note seems to be rather similar in the samples checked.

At the other hand, in comparison with other races south of the Amazon, capistratus seems to reach a higher pace. Also, there is more a tendency for the song going up and down in pitch, rather than going down in pitch in other races, possibly linked with a slightly different note shape. Differences are however not large at all, and may well blur further when a larger set of recordings is investigated, for all races south of the Amazon. 


\section{HANDBOOK OF THE \\ Alive}

\section{ORNITHOLOGICAL NOTES}
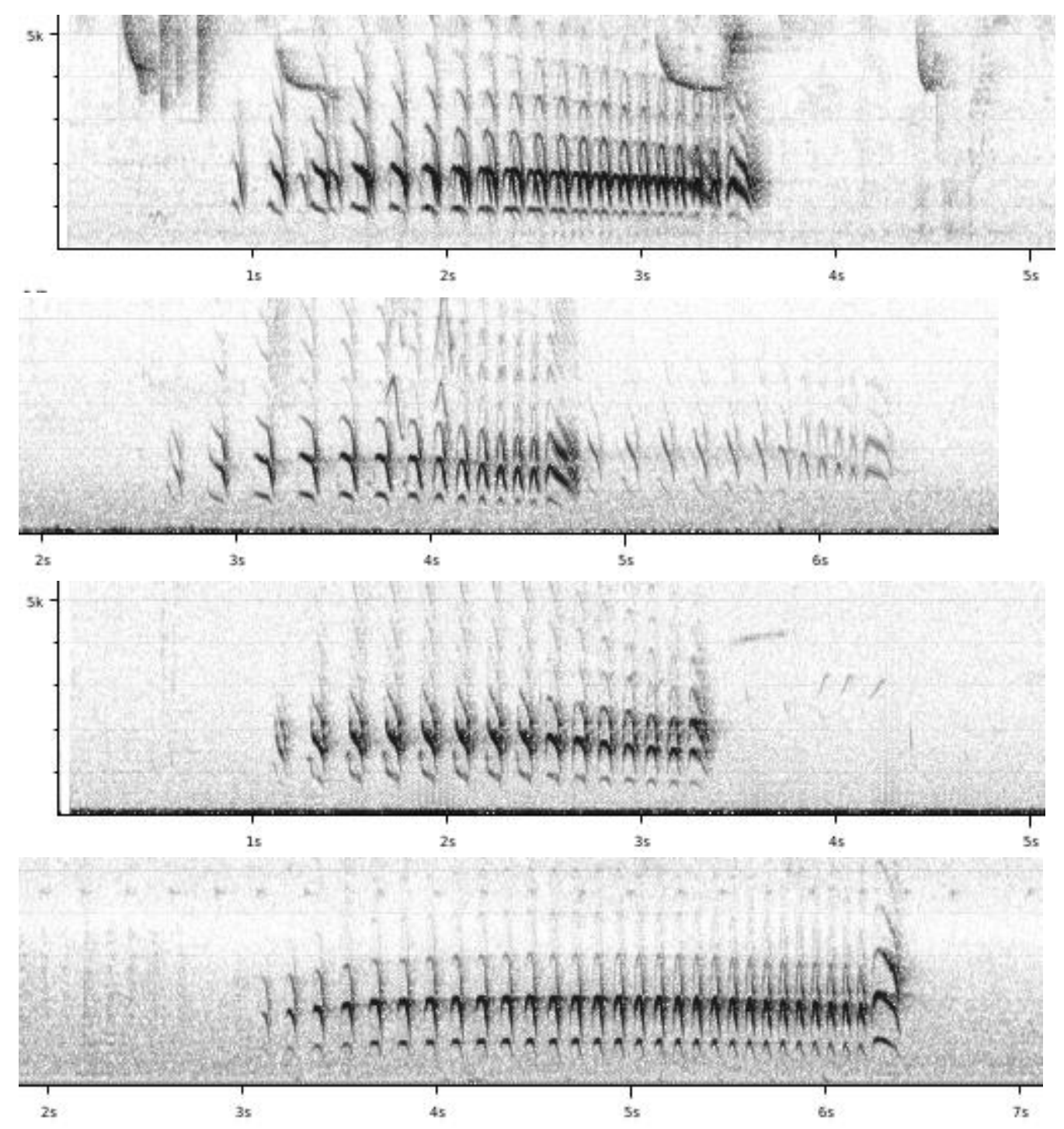

Figure 1: from top to bottom: typical loudsong of capistratus (2 examples), S of Amazon (Bolivia), $\mathrm{N}$ of Amazon (Mexico)

From the above, we can conclude that there is no parameter where capistratus differs from birds $\mathrm{N}$ and $\mathrm{S}$ of Amazon with an effect size larger than 2 (needed to reach a score of 2).

There are however differences that reach a score of 1 :

capistratus has a last note which is on average lower in frequency, and which does not rise a lot versus the previous note. Also in the middle and end of the note series, the max.

frequency is lower. Other differences are in between $\mathrm{N}$ and $\mathrm{S}$ birds, and would thus be even less outspoken if these 2 groups were to be merged. Total score for capistratus vs. all others is thus 1 or 2 . 

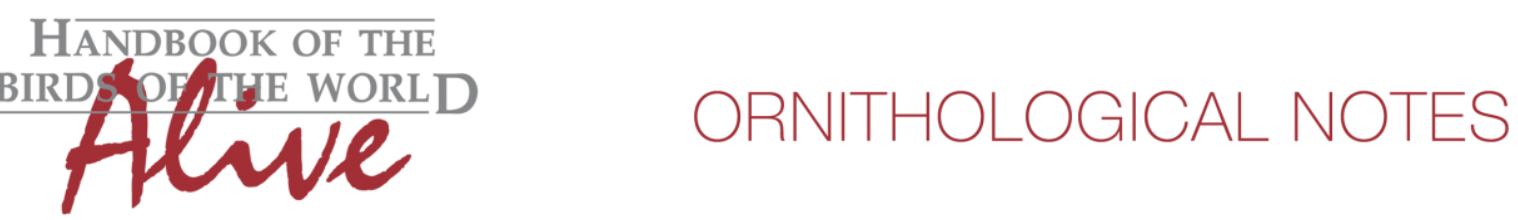

$\mathrm{N}$ and $\mathrm{S}$ birds differ mainly in number of notes (score 2), total length (2), etc. and would thus reach a total score of 4 (when capistratus is not included in S birds) or about 3 (when capistratus is included in $\mathrm{S}$ birds).

One could argue that with more recordings for $\mathrm{N}$ and $\mathrm{S}$ groups, differences may get less distinct. However, the recordings were taken randomly from a wide range, and we did not distinguish between male/female song or whether playback was used or not, which typically increases the variability. All in all, this score is thus quite representative we believe, and reflects a clear but moderate difference in loudsong between birds north and south of the Amazon river.

This note was finalized on 31st August 2015, using sound recordings available on-line at that moment. We would like to thank in particular the many sound recordists who placed their recordings for this species on XC.

\section{References}

Assis, C.P., Raposo, M.A., Stopiglia, R. and Parrini, R. (2007). Validation of Thamnophilus capistratus Lesson, 1840 (Passeriformes: Thamnophilidae). Auk 124(2): 665-676.

Tobias, J.A., Seddon, N., Spottiswoode, C.N., Pilgrim, J.D., Fishpool, L.D.C. \& Collar, N.J. (2010). Quantitative criteria for species delimitation. Ibis 152(4): 724-746.

\section{Recommended citation}

Boesman, P. (2016). Notes on the vocalizations of Barred Antshrike (Thamnophilus doliatus). HBW Alive Ornithological Note 53. In: Handbook of the Birds of the World Alive. Lynx Edicions, Barcelona. (retrieved from http://www.hbw.com/node/931932 on 30 April 2016). 